THE JOURNAL OF INFECTIOUS DISEASES - VOL. 156, NO. 1 - JULY 1987

(C) 1987 by The University of Chicago. All rights reserved. $0022-1899 / 87 / 5601-0019 \$ 01.00$

\title{
Single-Dose Rifampin Prophylaxis for Experimental Endocarditis Induced by High Bacterial Inocula of Viridans Streptococci
}

\author{
R. Malinverni, J. Bille, and M. P. Glauser
}

From the Department of Internal Medicine, Division of
Infectious Diseases, Centre Hospitalier Universitaire
Vaudois, Lausanne, Switzerland

In rats challenged with viridans streptococci poorly susceptible to antibiotic killing, single doses of antibiotics only prevent endocarditis induced by bacterial inoculum sizes that produce disease in $90 \%$ of control animals ( $\left(\mathrm{ID}_{90}\right)$ : additional doses are required to protect against inocula exceeding the $\mathrm{ID}_{90}$. We investigated whether single-dose rifampin would extend the efficacy of single-dose prophylaxis to inocula exceeding the ID $_{90}$. We used two strains of viridans streptococci highly susceptible to killing by rifampin and two resistant strains. All rats were injected with 10-1,000 times the $\mathrm{ID}_{90}$ of the four strains. Single-dose rifampin successfully prevented endocarditis due to all four strains. A few prophylaxis failures were observed after challenge with the two poorly susceptible strains, but in vivo emergence of resistant variants did not account for these failures. Thus, rifampin was the first antibiotic given as a single dose that successfully prevented experimental streptococcus endocarditis after challenge with high bacterial inocula.

Experimental streptococcus endocarditis can be successfully prevented by single doses of cell wall-active antibiotics like amoxicillin and vancomycin. When these antibiotics do not rapidly kill the bacteria used for challenge, however, the efficacy of singledose prophylaxis is limited to the animals challenged with the lowest bacterial inoculum that infects $90 \%$ of controls $\left(\mathrm{ID}_{90}\right)$ [1-3]. Isolates of viridans streptococci poorly susceptible to the bactericidal action of cell wall-active antibiotics are increasingly reported from patients with endocarditis [4] and among other clinical isolates of $\alpha$-hemolytic streptococci [5]. Against these bacteria, even a single dose of a synergistic combination of amoxicillin plus gentamicin failed to protect animals challenged with inocula exceeding the $\mathrm{ID}_{90}[6]$, and successful prevention of endocarditis could only be achieved by administering multiple doses of antibiotics that provide sustained blood levels after bacterial challenge (R. M., P. Francioli, M. P. G., unpublished observations).

Received for publication 29 July 1986, and in revised form 14 January 1987.

This work was supported by grant 3.847 .083 from the Swiss National Foundation for Scientific Research and by a grant from Ciba-Geigy.

We thank Dr. O. Zak (Ciba-Geigy, Basel, Switzerland) for support and helpful advice, José Entenza and Marlyse Giddey for technical assistance, and Sylviane Bovey for typing the manuscript.

Please address requests for reprints to Dr. M. P. Glauser, Division of Infectious Diseases, Centre Hospitalier Universitaire Vaudois, 1011 Lausanne, Switzerland.
In the present experiments we tested the ability of rifampin to prevent experimental streptococcal endocarditis. We chose rifampin for two reasons. First, rifampin produces sustained blood levels in both rats and humans after single-dose administration $[7,8]$. This pharmacological property permitted us to investigate whether single-dose rifampin, unlike singledose amoxicillin or vancomycin, would prevent endocarditis induced by bacterial inocula higher than the ID ${ }_{90}$ of the test organisms. Second, rifampin has excellent in vitro activity against viridans streptococci [9]. We used single-dose rifampin prophylaxis against four different Streptococcus strains that were injected into rats at inocula $10-1,000$ times the $\mathrm{ID}_{90}$ of the strains.

\section{Materials and Methods}

Microorganisms. Four strains of viridans streptococci isolated from patients with endocarditis were used. Streptococcus intermedius and Streptococcus sanguis (originally provided by Dr. D. Durack, Duke University Medical School, Durham, NC) have previously been used in experiments in rabbits $[10,11]$ and in rats $[1-3,6,12]$. In addition, two strains of Streptococcus mitis, S. mitis 1000 [6] and S. mitis 518 , were selected. These strains were selected because, from 23 strains of $\alpha$-hemolytic streptococci isolated from patients with bacterial endocarditis in our hospital, $S$. mitis 1000 and $S$. mitis 518 were the most susceptible to the bactericidal action of rifampin. 
MICs, MBCs, and rates of killing. The MICs of rifampin (Ciba-Geigy, Basel, Switzerland) for the four test organisms were determined by a standard broth-dilution procedure [13] using an inoculum of $10^{5}$ organisms from an overnight culture. The MBCs were determined by subculturing onto blood agar plates 10-fold and 100-fold broth dilutions of a 0.1 $\mathrm{ml}$ sample from each dilution showing no turbidity after $18 \mathrm{hr}$ of incubation. This dilution procedure was used to avoid the carryover of antibiotic, a phenomenon that can give falsely low MBCs. After $48 \mathrm{hr}$ of incubation the number of colonies on each plate was counted, and the MBC was determined as the lowest dilution of antibiotic that showed $99.9 \%$ killing.

Using a concentration of $10 \mu \mathrm{g}$ of rifampin $/ \mathrm{ml}$, we determined the rates of killing of the four test organisms in tryptic-soy broth (Difco, Detroit) by using a $10^{5}$ inoculum from an overnight culture. A concentration of $10 \mu \mathrm{g}$ of rifampin $/ \mathrm{ml}$ was chosen because it was similar to peak serum levels in rats after receiving $20 \mathrm{mg}$ of rifampin $/ \mathrm{kg} \mathrm{sc}$ and in humans after receiving $600 \mathrm{mg}$ orally $[8,14]$. At various times after inoculating the bacteria into the antibiotic-containing broth, $10^{-1}, 10^{-3}$, and $10^{-5} \mathrm{di}-$ lutions of a $0.1-\mathrm{ml}$ sample were subcultured onto blood agar plates and were incubated for $48 \mathrm{hr}$ before colony counts were done.

Serum levels and activities. Serum levels of rifampin were determined by a standard agar-diffusion technique using Sarcina lutea (ATCC 9341) as the test organism and antibiotic medium no. 1 (Difco) [15]. Normal rat serum was used as the diluent. The samples were taken $2,4,8,12$, and $24 \mathrm{hr}$ after an sc injection of $20 \mathrm{mg}$ of rifampin $/ \mathrm{kg}$ (water-soluble rifampin sodium salt; Ciba-Geigy) into groups of five rats for each time point.

Serum inhibitory activity (SIA) and serum bactericidal activity (SBA) for $S$. intermedius, $S$. sanguis, $S$. mitis 1000 , and $S$. mitis 518 were determined 4, 8,12 , and $24 \mathrm{hr}$ after an sc injection of $20 \mathrm{mg}$ of rifampin/ $\mathrm{kg}$ by standard methods [16], using an inoculum of $10^{5} \mathrm{cfu} / \mathrm{ml}$ for each strain. Subcultures were performed on blood agar plates by plating 10 fold and 100-fold dilutions of a $0.1-\mathrm{ml}$ sample of each dilution. The SIA was the highest serum dilution inhibiting visible bacterial growth, and the SBA was the highest serum dilution providing $99.9 \%$ killing of the original inoculum after $18 \mathrm{hr}$ of incubation.

Rifampin-resistant variants in vitro. Because two strains of viridans streptococci, S. sanguis and S. in- termedius, were not susceptible to the bactericidal action of rifampin, we investigated whether the lack of bacterial killing was due to the presence of rifampin-resistant subpopulations among these two strains. Experiments were performed as previously described to determine rates of killing. Briefly, using a $10^{6}$ bacterial inoculum from an overnight culture, we determined the rates of killing of $S$. intermedius and $S$. sanguis by using a concentration of $10 \mu \mathrm{g}$ of rifampin $/ \mathrm{ml}$. Before and after 12 and $24 \mathrm{hr}$ of exposure to rifampin, $0.1 \mathrm{ml}$ of undiluted $10^{-2}, 10^{-4}$, and $10^{-6}$ dilutions of control and rifampin-exposed vials were subcultured onto blood agar plates and onto plates containing 1,10 , and $100 \mu \mathrm{g}$ of rifam$\mathrm{pin} / \mathrm{ml}$. The plates were incubated for $48 \mathrm{hr}$ before colonies were counted. We used an additional $10^{8}$ cfu inoculum to search for rifampin-resistant variants in the initial inoculum (i.e., without prior exposure to the drug).

Rifampin-resistant variants in vivo. After the rats were killed, 0.1-ml samples of undiluted homogenates of vegetation suspended in $0.85 \% \mathrm{NaCl}$ from rats given rifampin prophylaxis were directly plated onto blood agar plates containing 1,10 , and $100 \mu \mathrm{g}$ of rifampin $/ \mathrm{ml}$. The plates were incubated for $48 \mathrm{hr}$ before the colonies were counted.

Adhesion of S. intermedius and S. sanguis to platelet-fibrin matrices. Experiments were performed by using an in vitro assay system that simulated nonbacterial thrombotic vegetations, as described previously [17]. The aim of these experiments was to investigate in vitro whether inhibition of bacterial adherence was a likely mechanism for successful rifampin prophylaxis against the two Streptococcus strains poorly susceptible to killing. In brief, cultures of $S$. intermedius and $S$. sanguis were grown overnight in tryptic-soy broth and suspended at a final concentration of $10^{4} \mathrm{cfu} / \mathrm{ml}$ in PBS supplemented with $10 \mu \mathrm{g}$ of rifampin $/ \mathrm{ml}$. Control bacteria were suspended in PBS alone. The suspensions were immediately poured into petri dishes containing the fibrin-platelet matrices and were incubated for $5 \mathrm{~min}$ at $37 \mathrm{C}$ in a shaking incubator. The supernatant was then removed, and the matrices were washed two times for $5 \mathrm{~min}$ each with rifampin or PBS alone. This total time of exposure to rifampin (15 min) was chosen to simulate the mean duration of bacteremia after intravenous challenge, during which time inhibition of adherence has to occur if it is to prevent endocarditis [2]. The petri dishes were then washed 10 times for 1 min each with PBS alone, 
a procedure used to rapidly and completely eliminate rifampin from the matrices.

Endocarditis. Sterile vegetations were produced in female Wistar rats $(180-200 \mathrm{~g})$ by a previously described method [1]. In brief, a polyethylene catheter was inserted via the right carotid artery through the aortic valve into the left ventricle and secured with a silk ligature. Twenty-four hours after this procedure, rats were injected iv with $0.5 \mathrm{ml}$ of $0.85 \% \mathrm{NaCl}$ containing $10^{8}$ cfu of $S$. mitis 518 , S. intermedius, or $S$. sanguis test organisms or containing $10^{7} \mathrm{cfu}$ of $S$. mitis 1000 from an overnight culture.

The ID ${ }_{90}$ was determined as previously described [3]. In brief, the $\mathrm{ID}_{90}$ of $S$. intermedius and $S$. mitis 1000 was $10^{5} \mathrm{cfu} / \mathrm{ml}$; of $S$. sanguis, $10^{6} \mathrm{cfu} / \mathrm{ml}$; and of $S$. mitis $518,10^{7} \mathrm{cfu} / \mathrm{ml}$. Thus, the inocula used in the prophylaxis experiments were 1,000 times the ID $_{90}$ of $S$. intermedius, 100 times the ID ${ }_{90}$ of $S$. sanguis and $S$. mitis 1000, and 10 times the $\mathrm{ID}_{90}$ of $S$. mitis 518.

For $S$. mitis $1000, S$. intermedius, and $S$. sanguis, we have previously established [6] that single-dose amoxicillin prophylaxis failed against inocula higher than the $\mathrm{ID}_{90}$. For $S$. mitis 518, we established a similar phenomenon by using an inoculum size of $10^{8}$ $\mathrm{cfu} / \mathrm{ml}$.

Prophylaxis. Four hours before challenge with the four test organisms, groups of rats were injected sc with either $20 \mathrm{mg}$ of rifampin $/ \mathrm{kg}$ or $0.85 \% \mathrm{NaCl}$ alone (controls). The 4-hr interval between rifampin injection and bacterial challenge was chosen so that bacteria were injected at the time of peak rifampin levels.
Evaluation of infection. Rats given $0.85 \% \mathrm{NaCl}$ (controls) were killed $72 \mathrm{hr}$ after bacterial challenge. Rats given rifampin prophylaxis were killed seven days after bacterial challenge, a period that permitted the full development of endocarditis if rifampin prophylaxis failed.

After the rats were killed, aortic vegetations were excised, weighed, homogenized in $1 \mathrm{ml}$ of $0.85 \%$ $\mathrm{NaCl}$, serially diluted, and plated. Colony counts were determined after $48 \mathrm{hr}$ of incubation at $37 \mathrm{C}$. This method permitted us to detect $10^{2} \mathrm{cfu}$ of bacte$\mathrm{ria} / \mathrm{g}$ of vegetation.

Statistics. The $\chi^{2}$ test with Yates' correction and the unpaired Student's $t$ test were used for statistical comparisons.

\section{Results}

MICs, MBCs, and rates of killing. The MICs and MBCs, respectively, of rifampin for the four test organisms were 0.016 and $0.032 \mu \mathrm{g} / \mathrm{ml}$ for $S$. mitis 1000 , 0.008 and $0.064 \mu \mathrm{g} / \mathrm{ml}$ for $S$. mitis $518,0.032$ and $16 \mu \mathrm{g} / \mathrm{ml}$ for $S$. intermedius, and 0.032 and $32 \mu \mathrm{g} / \mathrm{ml}$ for $S$. sanguis. Thus, the first two strains exhibited $\mathrm{MBC}$ values close to their MICs, in contrast to the latter two strains, which showed higher MBC values.

The rates of in vitro killing of the four test organisms by $10 \mu \mathrm{g}$ of rifampin $/ \mathrm{ml}$ (simulating peak serum levels $4 \mathrm{hr}$ after prophylaxis) are shown in figure 1. Bacterial counts of both $S$. intermedius and $S$. sanguis were not significantly reduced by peak concentrations of rifampin over $24 \mathrm{hr}$ of incubation,
Figure 1. Rates of in vitro killing of four strains of viridans streptococci by $10 \mu \mathrm{g}$ of rifampin $/ \mathrm{ml}$ (a concentration similar to peak serum levels in rats 4 hr after receiving $20 \mathrm{mg}$ of rifampin $/ \mathrm{kg}$ sc). I, S. sanguis; $2, S$. intermedius; 3 , S. mitis 1000; and 4, S. mitis 518 .

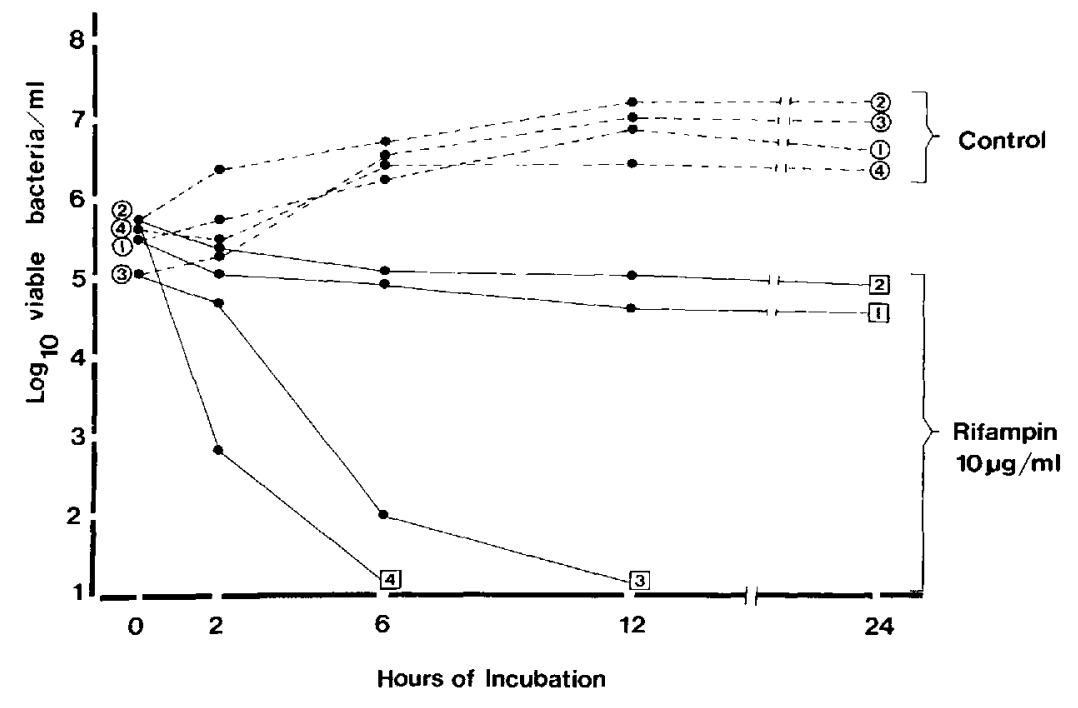


whereas both strains of $S$. mitis were killed within 6 and $12 \mathrm{hr}$.

Rifampin-resistant variants of S. sanguis and $S$. intermedius. When $S$. sanguis was tested at an inoculum of $10^{8} \mathrm{cfu}$, the frequency of resistant variants without prior exposure to rifampin was $10^{-7}$ (MIC, $\geqslant 256 \mu \mathrm{g} / \mathrm{ml}$ ). At the $10^{6} \mathrm{cfu}$ inoculum, no rifampin-resistant variants could be detected without prior exposure to rifampin. In contrast, inocula exposed to rifampin for $12 \mathrm{hr}$ showed a $10^{-3}$ frequency of resistant variants (MIC, $\geqslant 512 \mu \mathrm{g} / \mathrm{ml}$ ). After $24 \mathrm{hr}$ of exposure, all the colonies tested were highly resistant to rifampin.

When $S$. intermedius was tested at inocula of $10^{6}$ and $10^{8} \mathrm{cfu}$, no rifampin-resistant variants were detected without prior exposure to rifampin. When a $10^{6} \mathrm{cfu}$ inoculum was exposed to rifampin, however, the frequency of resistant variants was $10^{-2}$ (MIC, $\geqslant 1,024 \mu \mathrm{g} / \mathrm{ml}$ ) after $12 \mathrm{hr}$ of exposure, and all the colonies tested were highly resistant to rifampin (MIC, $512-1,024 \mu \mathrm{g} / \mathrm{ml}$ ) after $24 \mathrm{hr}$ of exposure.

Thus, the bacteriostatic effect of rifampin on $S$. intermedius and $S$. sanguis, observed when performing killing curves, was due to the selection of variants highly resistant to rifampin.

MICs and MBCs of 23 strains of viridans streptococci. The MICs of rifampin for all 23 strains of $\alpha$-hemolytic streptococci isolated from patients with endocarditis were $<0.064 \mu \mathrm{g} / \mathrm{ml}$. Nineteen $(83 \%)$ of 23 strains had MBC values that exceeded their $\mathrm{MIC}$ values $>32$ times.

Serum levels and activities. Two hours after rats were injected sc with $20 \mathrm{mg}$ of rifampin $/ \mathrm{kg}$, the mean $\pm \mathrm{SD}$ serum level was $9.1 \pm 1.4 \mu \mathrm{g} / \mathrm{ml}$; after $4 \mathrm{hr}$ this value was $14.2 \pm 1.26 \mu \mathrm{g} / \mathrm{ml}$. Thus, peak serum levels were observed $4 \mathrm{hr}$ after injection. The mean \pm SD values 8,12 , and $24 \mathrm{hr}$ after injection were $10.9 \pm 1.22 \mu \mathrm{g} / \mathrm{ml}, 7.6 \pm 0.8 \mu \mathrm{g} / \mathrm{ml}$, and $0.4 \pm$ $0.1 \mu \mathrm{g} / \mathrm{ml}$, respectively.

After 36 rats were injected sc with $20 \mathrm{mg}$ of rifampin $/ \mathrm{kg}$, no SBA against $S$. intermedius or $S$. sanguis could be detected at any time; however, SIAs of $>1: 16$ could be detected until $12 \mathrm{hr}$ after injection. Against $S$. mitis 518, the mean SBAs were 1:16, $1: 8$, and $1: 4$ at 4,8 , and $12 \mathrm{hr}$, respectively, after injecting five rats at each time point. Against $S$. mitis 1000 , the SBAs were $1: 8,1: 4$, and $1: 2$ at 4,8 , and $12 \mathrm{hr}$ after injection, respectively. Thus, only serum inhibitory titers were detected against the tolerant strains, whereas serum bactericidal titers were detected for up to $12 \mathrm{hr}$ against the susceptible strains.
Prophylaxis with rifampin. Figure 2 shows the results of single-dose rifampin prophylaxis against the four Streptococcus strains. Rifampin completely prevented endocarditis induced by the two strains that were highly susceptible to killing by rifampin (S. mitis 1000 and S. mitis 518); the vegetations from all 38 animals were sterile seven days after bacterial challenge ( $P<.001$ when compared with controls). Single-dose rifampin also significantly protected $(P<.001$ for both strains when compared with controls) against endocarditis induced by the two strains not killed by rifampin (S. intermedius and $S$. sanguis); however, prophylaxis failures were observed in seven of 25 rats challenged with $S$. intermedius and in four of 23 rats challenged with $S$ sanguis. The mean bacterial densities of the vegetations from the prophylaxis failures were significantly less than those in controls $(P<.003)$, despite the fact that all animals given rifampin were killed seven days after administration of the antibiotic.

Adhesion of S. intermedius and S. sanguis to platelet-fibrin matrices. Because $S$. intermedius and $S$. sanguis were not killed by rifampin in vitro, we investigated whether successful prophylaxis with rifampin might have been mediated through diminished adherence of the organisms to cardiac valves. We therefore tested the influence of rifampin on the in vitro adherence of these two microorganisms to platelet-fibrin matrices. When incubated in vitro with $10 \mu \mathrm{g}$ of rifampin $/ \mathrm{ml}$ for $15 \mathrm{~min}$, the adherence ratio (mean \pm SD of 60 determinations) of $S$. intermedius was $0.091 \pm 0.068$ for controls (PBS alone) and $0.14 \pm 0.088$ for rifampin-incubated organisms $(P>.05$, Student's $t$ test). For $S$. sanguis, the mean adherence ratio (60 determinations) was $0.072 \pm$ 0.034 for controls and $0.063 \pm 0.035$ for rifampinincubated organisms ( $P>.05$, Student's $t$ test). Thus, rifampin did not significantly influence the in vitro adhesion of $S$. intermedius or $S$. sanguis to plateletfibrin matrices.

Rifampin-resistant variants in vivo. When samples of undiluted homogenates of the vegetations from the prophylaxis failures were plated onto rifampin-containing blood agar plates, none of the seven $S$. intermedius failures and only one of the four $S$. sanguis failures showed decreased susceptibility to rifampin. In the latter case, a few $S$. sanguis colonies grew on plates containing $1 \mu \mathrm{g}$ of rifampin $/ \mathrm{ml}$, but none grew on plates containing 10 or $100 \mu \mathrm{g} / \mathrm{ml}$. Thus, only one of 11 vegetations that was not protected from infection by single-dose rifampin pro- 


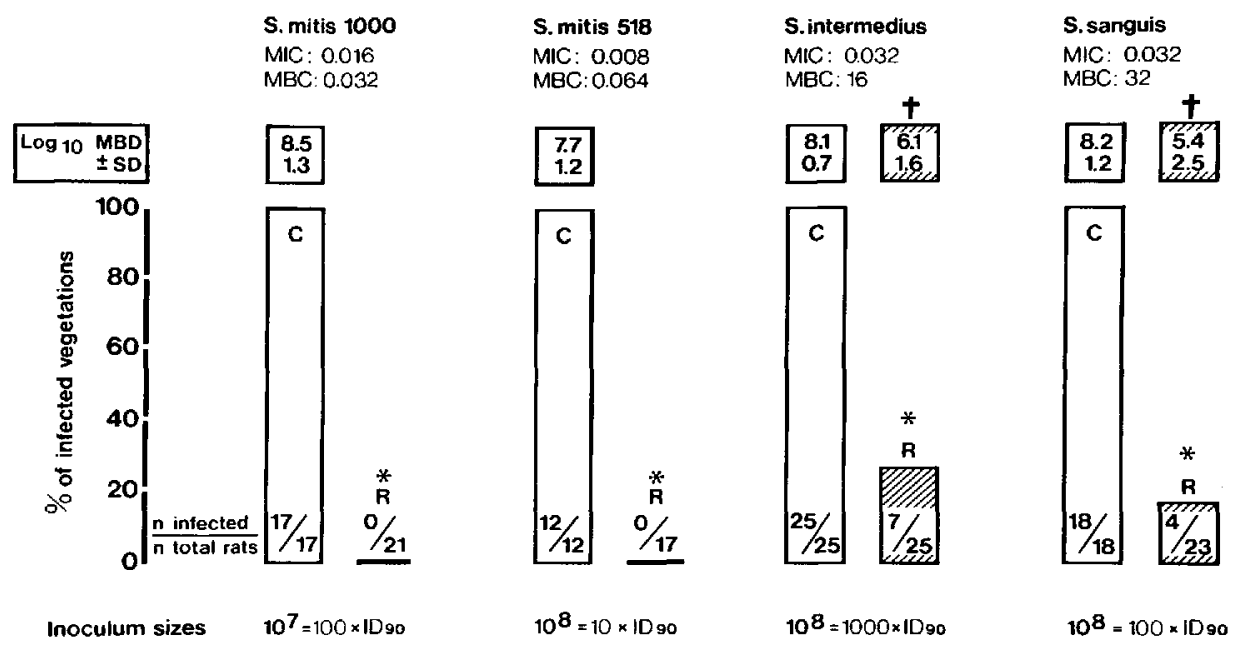

Figure 2. Incidence of endocarditis (number of rats with endocarditis/total number of rats challenged with each strain) in control $(C)$ rats and in rats given single-dose rifampin prophylaxis $(R) 4 \mathrm{hr}$ before challenge with four strains of

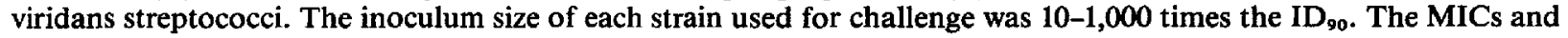
MBCs of rifampin are indicated for each strain. The mean $( \pm$ SD) bacterial densities $(M B D)$ recovered from vegetations (expressed in $\mathrm{cfu} / \mathrm{g}$ of vegetation) are indicated for each group. To compare the incidence of endocarditis in control rats to that in rats given rifampin prophylaxis, we calculated $P$ values by $\chi^{2}$ with Yates' correction; ${ }^{*}=P<.001$. To compare MBDs in controls to those in rats given rifampin prophylaxis, we calculated $P$ values by unpaired Student's $t$ test; $\dagger=P<.003$.

phylaxis harbored streptococci with decreased in vitro susceptibility to rifampin.

\section{Discussion}

Experiments in both rabbits and rats have shown that when animals are challenged with organisms poorly susceptible to antibiotic killing, successful prophylaxis conferred by single doses of antibiotics is limited to the $\mathrm{ID}_{90}$ and fails when the animals are challenged with inocula higher than the $\operatorname{ID}_{90}[3,6]$. In the latter condition, endocarditis can be prevented only by prolonged levels of antibiotics, such as are achievable after multiple doses [18; R. M., P. Francioli, M. P. G, unpublished observations]. Because most strains of viridans streptococci appear to be poorly susceptible to the bactericidal action of cell wall-active antibiotics $[4,5]$, drugs providing high and prolonged serum antibiotic activity after a single dose should be investigated for preventing experimental bacterial endocarditis after challenge with heavy loads of bacteria.

The present results show that single-dose rifampin, which produces SIAs for $>12 \mathrm{hr}$ for all four strains tested, provided successful prophylaxis against very high bacterial inocula, irrespective of whether the organisms used for challenge were killed rapidly by the drug.

Against challenge with both $S$. mitis 1000 and S. mitis 518 (the two strains highly susceptible to killing by rifampin, as indicated by the high serum bactericidal levels in vivo and by time-kill curves in vitro), it is likely that protection was provided through bacterial killing. Previous experiments in rats [3] have shown that when bacteria used for challenge are killed rapidly enough in vitro that the intravenous bacterial inoculum is likely to be killed upon exposure to serum bactericidal levels in vivo, successful prophylaxis is independent of the inoculum size.

Against $S$. sanguis and $S$. intermedius, rapid bacterial killing could not account for successful prophylaxis because neither the serum bactericidal activity nor the in vitro exposure for $24 \mathrm{hr}$ of both strains to peak concentrations of rifampin $(10 \mu \mathrm{g} / \mathrm{ml})$ indicated a significant reduction in bacterial numbers. In fact, it was established in vitro that this lack of bacterial killing was due to the selection of rifampin-resistant variants, a phenomenon observed in only one of 23 rats infected with $10^{8} \mathrm{cfu}$ of $S$. sanguis and given rifampin prophylaxis and in none of 25 rats infected with $10^{8} \mathrm{cfu}$ of $S$. intermedius and given rifampin prophylaxis. 
In the absence of bacterial killing, one mechanism of successful endocarditis prophylaxis has been postulated to be antibiotic-mediated decreased adherence of organisms to damaged valvular endothelium $[2,17,19]$. By using an in vitro assay system simulating damaged valvular endothelium, Scheld et al. [17], as well as others [19], have shown that various cell wall-active antibiotics prevented the adherence of $S$. sanguis to platelet-fibrin matrices. Rifampin did not, however, influence the in vitro adhesion ratio of S. sanguis in those experiments, nor did it in the present experiments, when concentrations of rifampin $>156$ times the MICs of the two strains were used. Thus, the reduction of bacterial adherence by rifampin prophylaxis was not a likely mechanism operating to prevent endocarditis due to $S$. intermedius and $S$. sanguis in the present experiments.

Recent observations [18] have provided evidence that in the absence of rapid bacterial killing, the inhibition of growth of bacteria attached to the vegetations after intravenous challenge may be an important mechanism of protection after antibiotic prophylaxis, by permitting release of the bacteria that had colonized the vegetations. The longer the duration of growth inhibition, the greater the likelihood of successful prophylaxis after challenge with inocula exceeding the $\mathrm{ID}_{90}$ [18]. In the present experiments, single-dose rifampin provided serum levels above the MIC for both $S$. intermedius and $S$. sanguis for at least $12 \mathrm{hr}$. Moreover, it is likely that rifampin provided growth inhibition for a longer duration than the mere period of circulating rifampin levels: Bacterial numbers in vegetations from prophylaxis failures seven days after administration of rifampin were significantly lower than in controls, a result suggesting a prolonged in vivo suppression of bacterial growth. A similar phenomenon has been observed after amoxicillin prophylaxis of streptococcus endocarditis [3] and after rifampin prophylaxis of a foreign-body infection due to Staphylococcus aureus [20]. Moreover, a prolonged in vitro postantibiotic effect has been demonstrated for rifampin-exposed $S$. aureus [21].

The rapid development of resistant variants after administration of rifampin is a major concern. The lack of in vitro bactericidal activity of rifampin against $S$. sanguis and $S$. intermedius was due to the emergence of rifampin-resistant subpopulations after a long exposure to high concentrations of rifampin. In only one instance in vivo, however, could we detect moderately resistant $S$. sanguis after rifam- pin prophylaxis, a phenomenon that is not significant when one considers the total of 48 rats that received rifampin before challenge with high bacterial inocula of $S$. sanguis and $S$. intermedius. The inability of the in vitro observation to predict the in vivo outcome of prophylaxis might be explained by the fact that in vivo, both rifampin levels and duration of antibiotic exposure were less pronounced than in the in vitro experiments. It might be hypothesized that, in vivo, rifampin inhibited the growth of (or slowly killed) the susceptible subpopulation (i.e., the population with low MICs) of S. intermedius and $S$. sanguis and thus accounted for successful prophylaxis without selection of resistant variants.

In studies by others [14], the emergence of resistant strains was not observed in vivo when singledose rifampin was used for prophylaxis of experimental Staphylococcus epidermidis endocarditis, nor was it observed after short-term treatment of experimental staphylococcus osteomyelitis $(O$. Zak, personal communication). In contrast, the emergence of rifampin resistance has been detected in experimental models when high numbers of bacteria were exposed to rifampin during prolonged periods of time [22-24]. Although these latter observations do not support the use of the prolonged administration of rifampin as a single therapeutic agent, short-term, single-dose rifampin prophylaxis might retain full effectiveness.

In conclusion, single-dose rifampin prophylaxis of experimental streptococcus endocarditis extended the protection to bacterial inocula exceeding, by far, the ID 90 of the test strains. The protection was independent of whether or not the organisms were susceptible to bacterial killing by rifampin. Thus, rifampin was the first prophylactic agent that provided a wide margin of safety against experimental streptococcus endocarditis when given as a single dose.

\section{References}

1. Heraief E, Glauser MP, Freedman LR. Vancomycin prophylaxis of streptococcal endocarditis in rats. In: Nelson JD, Grassi C, eds. Current chemotherapy and infectious disease. Vol 2. American Society for Microbiology, Washington, D. C., 1980:911-3

2. Bernard J-P, Francioli P, Glauser MP. Vancomycin prophylaxis of experimental Streptococcus sanguis. Inhibition of bacterial adherence rather than bacterial killing. J Clin Invest 1981;68:1113-6

3. Glauser MP, Bernard JP, Moreillon P, Francioli P. Successful single-dose amoxicillin prophylaxis against experimental 
streptococcal endocarditis: evidence for two mechanisms of protection. J Infect Dis 1983;147:568-75

4. Meylan PR, Francioli P, Glauser MP. Discrepancies between $\mathrm{MBC}$ and actual killing of viridans group streptococci by cell-wall-active antibiotics. Antimicrob Agents Chemother 1986;29:418-23

5. Handwerger S, Tomasz A. Antibiotic tolerance among clinical isolates of bacteria. Rev Infect Dis 1985;7:368-86

6. Francioli P, Moreillon P, Glauser MP. Comparison of single doses of amoxicillin or amoxicillin-gentamicin for the prevention of endocarditis caused by Streptococcus faecalis and by viridans streptococci. J Infect Dis 1985;152:83-9

7. Furesz $\mathrm{S}$. Chemical and biological properties of rifampicin. Antibiot Chemother 1970;16:316-51

8. Acocella G. Clinical pharmacokinetics of rifampicin. Clin Pharmacokinet 1978;3:108-27

9. Bourgault A-M, Wilson WR, Washington JA II. Antimicrobial susceptibilities of species of viridans streptococci. J Infect Dis 1979;140:316-21

10. Durack DT, Petersdorf RG. Chemotherapy of experimental streptococcal endocarditis. I. Comparison of commonly recommended prophylactic regimens. J Clin Invest 1973; 52:592-8

11. Pelletier LL Jr, Durack DT, Petersdorf RG. Chemotherapy of experimental streptococcal endocarditis. IV. Further observations on prophylaxis. J Clin Invest 1975;56:319-30

12. Glauser MP, Francioli P. Successful prophylaxis against experimental streptococcal endocarditis with bacteriostatic antibiotics. J Infect Dis 1982;146:806-10

13. Jones RN, Barry AL, Gavan TL, Washington JA II. Susceptibility tests: microdilution and macrodilution broth procedures. In: Lennette EH, Balows A, Hausler WJ Jr, Shadomy HJ, eds. Manual of clinical microbiology. 4th ed. Washington, DC: American Society for Microbiology, 1985: 972-7

14. Archer GL, Vazquez GJ, Johnston JL. Antibiotic prophylaxis of experimental endocarditis due to methicillinresistant Staphylococcus epidermidis. J Infect Dis 1980; 142:725-31
15. Anhalt JP. Assays for antimicrobial agents in body fluids. In: Lennette EH, Balows A, Hausler WJ, Shadomy HJ, eds. Manual of clinical microbiology. 4th ed. Washington, DC: American Society for Microbiology, 1985:1009-114

16. Schoenknecht FD, Sabath LD, Thornsberry C. Susceptibility tests: special tests. In: Lennette EH, Balows A, Hausler WJ, Shadomy HJ, eds. Manual of clinical microbiology. 4th ed. Washington, DC: American Society for Microbiology, 1985:1000-8

17. Scheld WM, Valone JA, Sande MA. Bacterial adherence in the pathogenesis of endocarditis. Interaction of bacterial dextran, platelets, and fibrin. J Clin Invest 1978; 61:1394-404

18. Moreillon P, Francioli P, Overholser D, Meylan P, Glauser MP. Mechanisms of successful amoxicillin prophylaxis of experimental endocarditis due to Streptococcus intermedius. J Infect Dis 1986;154:801-7

19. Lowy FD, Chang DS, Neuhaus EG, Horne DS, Tomasz A, Steigbigel NH. Effect of penicillin on the adherence of Streptococcus sanguis in vitro and in the rabbit model of endocarditis. J Clin Invest 1983;71:668-75

20. Tshefu K, Zimmerli W, Waldvogel FA. Short-term administration of rifampin in the prevention or eradication of infection due to foreign bodies. Rev Infect Dis 1983;5:S474-80

21. Bundtzen RW, Gerber AU, Cohn DL, Craig WA. Postantibiotic suppression of bacterial growth. Rev Infect Dis 1981;3:28-37

22. Sande MA, Johnson ML. Antimicrobial therapy of experimental endocarditis caused by Staphylococcus aureus. J Infect Dis 1975;131:367-75

23. Norden CW. Experimental osteomyelitis. IV. Therapeutic trials with rifampin alone and in combination with gentamicin, sisomicin, and cephalothin. J Infect Dis 1975;132:493-9

24. Mandell GL, Moorman DR. Treatment of experimental staphylococcal infections: effect of rifampin alone and in combination on development of rifampin resistance. Antimicrob Agents Chemother 1980;17:658-62 